\title{
EL DEBATE IUSFILOSÓFICO CUBANO DE LA SEGUNDA MITAD DEL SIGLO XIX*
}

\author{
LEGAL PHILOSOPHY DEBATE IN CUBA \\ IN THE SECOND HALF OF THE NINETEENTH CENTURY
}

Vladimir PITA SIMóN**

\section{Resumen:}

El pensamiento filosófico sobre el derecho y el Estado es uno de los elementos fundamentales en la conformación de la identidad nacional cubana. El presente artículo se ocupa de los principales referentes iusfilosóficos contextuales que incidieron en la conformación del discurso político-jurídico cubano de la segunda mitad del siglo XIX, y de la construcción de los contenidos específicos del pensamiento filosófico del derecho. Dentro de este análisis ocupa un lugar preponderante el conjunto de ideas iusfilosóficas martianas, las que se han convertido en un elemento central en la legitimación de las ideologías institucionales en la isla.

\section{Palabras clave:}

Filosofía del derecho, iusnaturalismo, cultura política, recepción del derecho, José Martí, Cuba.

* Artículo recibido el 24 de mayo de 2013 y aceptado para su publicación el 15 de octubre de 2014.

** Profesor principal de Filosofía del Derecho, Sociología del Derecho e Introducción al estudio del pensamiento político-jurídico, en la Facultad de Derecho de la Universidad de Holguín, Cuba. Aspirante a Doctor en Ciencias Jurídicas por la Universidad de Oriente, Santiago de Cuba. E-mail: vpita80@yahoo.es,vpita@fh.uho. edu.cu. 


\author{
VLADIMIR PITA SIMÓN
}

\title{
Abstract:
}

Philosophical thought about Law and the State is essential to explain a national identity of the Cuban people. This article focuses on the salient scholars, within philosophy of law, that influenced political and legal discourse in Cuba during the second half of the 19th century, and the definition of particular issues relevant to legal philosophy. Within this analysis, there is a special place for the ideas of José Martí, ideas that constitute a crucial element for institutional ideologies in Cuba and its legitimacy.

Keywords:

Legal Philosophy, Natural Law Theory, Political Culture, Reception of Law, José Martí, Cuba. 
SumARIO: I. Introducción. II. El iusfilosofar latinoamericano. III. El iusnaturalismo conservador integrista. IV. El iusnaturalismo reformista de los autonomistas. V. El pensamiento iusfilosófico revolucionario de José Martí. VI. A manera de conclusiones. VII. Bibliografía.

\section{INTRODUCCIÓN}

El debate ideológico-jurídico de la segunda mitad del siglo XIX cubano está signado por el inicio del dilatado proceso de cuestionamiento de la hegemonía del iusnaturalismo racionalista propio de los dirigentes independentistas y la elite intelectual del autonomismo. Este debate sólo pudo lograr su resolución una vez dirimida la cuestión de la independencia, y ya adentradas las primeras décadas del siglo XX. El Pacto del Zanjón, que dio fin a la primera guerra de independencia cubana, abrió una etapa cualitativamente diferenciada dentro de la vida política en la isla de Cuba. El alto grado de polarización generado por la conflagración se canalizó a través de la creación de un nuevo espacio público, dentro del cual se manifestaron de forma extrema el sistema de contradicciones presente. ${ }^{1}$ El proceso de socialización política de estos años contribuyó a la creación de una cultura política basada en un andamiaje normativo de derechos y libertades que impactaron en el espacio público colonial y a sus redes de clientela política.

En un país donde la problemática social en esta etapa estuvo marcada por el proceso de disolución de la esclavitud, y por las nuevas formas de integración y marginación a los que fueron sometidos los ex esclavos, la idea del derecho se convierte en distintiva de los esfuerzos de los sectores intelectuales de una burguesía que daba sus primeros pasos en el establecimiento de los contenidos centrales

1 A partir de 1881 se permitió que por primera vez se accediera al despliegue parcial y muy limitado de un esquema liberal de la actividad política. La creación de los partidos políticos representó un cambio que marca cierto grado de madurez de las fuerzas políticas presentes en Cuba, y de complejización de los procesos de integración y diferenciación de las diferentes corrientes ideológicas. Cfr. Torre, Mildred de la, El autonomismo en Cuba 1878-1898, La Habana, Editorial de Ciencias Sociales, 1997, p. 15. 


\section{VLADIMIR PITA SIMÓN}

del nacionalismo cubano. Este sería la expresión ideológica principal del proceso de instauración y paulatina expansión de las relaciones capitalistas de producción en la isla, el cual generó un discurso de la justicia anclado en una formulación limitada del principio de igualdad jurídica.

\section{EL IUSFILOSOFAR LATINOAMERICANO}

El empuje de las incipientes relaciones capitalistas determinó que los países latinoamericanos, para la segunda mitad del siglo XIX, se adentraran en procesos de reformas liberales de sus sociedades, de sus economías y de la política. El enfrentamiento a las estructuras tradicionales en muchas ocasiones derivó en procesos violentos (revoluciones liberales), que dentro de sus programas declaraban como fin explícito la modernización de nuestras realidades a partir de los esquemas europeos. El carácter periférico y dependiente de la región determinó que la modernización capitalista reprodujera un esquema de inestabilidad y de precariedad política e institucional. La alianza existente entre los grandes propietarios agrícolas y el capital extranjero marcó el carácter dependiente del proceso de inserción en el mercado mundial, lo cual imposibilitó una acumulación autosostenida, paso indispensable para el surgimiento de modelos de capitalismo nacionales exitosos. Esta debilidad en la conformación del capitalismo latinoamericano se tradujo en una debilidad crónica de las estructuras republicanas. Durante toda la primera mitad del siglo XIX, y gran parte de la segunda, se tradujo esta incoherencia estructural latinoamericana, en una persistente inadecuación de los órdenes jurídicos a la realidad socioeconómica. La intelectualidad criolla diseñó diferentes salidas, cada una de las cuales correspondía con la posición que ocupara el pensador dentro del espectro ideológico existente. La filosofía del derecho adolecería de estas mismas características, mostrando una resistencia a las formulaciones autóctonas, aunque preclaras mentalidades señalaran la necesidad de ensayar nuevos caminos. En este periodo, que se extiende hasta comienzos del siglo XX, en América Latina apenas hallamos filosofías en el sentido de sistemas filosóficos, más bien encontramos un pensamiento filosófico entretejido con la literatura, el discurso político 
y social, o diluido en otras formas culturales autóctonas. La filosofía hegemónica fue el positivismo, lo que no oculta la presencia de otras importantes corrientes como el neotomismo, el krausismo y todas las variantes de recepción del idealismo alemán, especialmente el kantiano. En la filosofía del derecho latinoamericana de la época encontramos que gran parte de su contenido está compuesto por una especie de pensamiento iusfilosófico, que en muchas ocasiones no llega a constituirse en un cuerpo coherente con pretensiones sistémicas. En él ha prevalecido mayoritariamente el imperativo práctico político. La resolución de los problemas de la realidad social y política ha jugado un papel fundamental en la conformación de nuestra identidad político-jurídica, brindándole su sustento legitimador. El deseo por parte del sujeto latinoamericano de constituirse como ente autónomo, con una identidad propia frente a un mundo caótico donde lo europeo y lo norteamericano ejerce un rol de dominio, vendría a ser la causa última de su existencia y necesidad.

Ya desde los comienzos del desarrollo de los procesos independentistas, había prevalecido la influencia de la filosofía del derecho francesa en toda América Latina, y esto significó el predomino del iusnaturalismo racionalista francés del siglo XVIII. Todas las figuras dirigentes de los movimientos de la Independencia estuvieron inspiradas por las teorías de Montesquieu. A manera de singularidad, las ideas iusfilosóficas de Rousseau ejercieron una relativa influencia el pensamiento político de figuras más arraigadas en el sentir popular, como es el caso de Simón Bolívar. Al mismo tiempo se encuentra señales de la presencia del utilitarismo inglés de Stuart Mill, y más tarde, del eclecticismo de Víctor Cousin.

Para la segunda mitad del siglo XIX latinoamericano, la fuente más importante de inspiración filosófica fue Augusto Comte (17981857). Su influencia prevaleció fundamentalmente en Argentina, Brasil, Chile, México y Cuba. Además podemos rastrear la influencia de las obras de Darwin (1809-1882), la Herbert Spencer (18201903), y la de Haeckel (1834-1919). En la lucha de los pensadores latinoamericanos contra las doctrinas teológicas y metafísicas, que habían preponderado desde la colonización del continente, fueron los argumentos antimetafísicos de Comte y Spencer los más utilizados. Esto estaba sustentado en la necesidad de la introducción de 


\section{VLADIMIR PITA SIMÓN}

modelos que rompieran el esquema de dominación en lo social, lo político y lo productivo legado por el sistema colonial español, además del gran prestigio que venían alcanzando las ciencias naturales a lo largo de todo el siglo XIX.

\section{EL IUSNATURALISMO CONSERVADOR INTEGRISTA}

En Cuba, las especificidades de la relación colonia-metrópoli imponían tensiones irresolubles al pensamiento político español, violentando en las más de las veces los contenidos desde los cuales se fundamentaban las posiciones más progresistas de los liberales peninsulares. Las ideas que legitimaron las relaciones de expoliación de la colonia cubana fueron siempre las más conservadoras. ${ }^{2}$ Encontramos la apoyatura ideológica de las posiciones integristas fundamentalmente en las fórmulas propias del tradicionalismo y el krausismo españoles, este último como parte del arsenal filosófico esgrimido por los liberales hispanos. ${ }^{3}$

La vertiente más conservadora de fundamentación del pensamiento colonialista fue el pensamiento tradicionalista español. Este partía de la idea, de profunda raíz católica, de que tanto el mundo como el conjunto de criaturas que en él existen, están sometidas a las reglas establecidas por Dios, creador absoluto de la realidad, las cuales introdujo tanto en el orden de lo físico, como en el de la moral. Para esta cosmovisión el hombre ocupa el más alto peldaño del orden universal, por lo cual es poseedor de derechos y deberes especiales. Dada la naturaleza racional del mismo, este puede moverse voluntariamente hacia fines conocidos, ya que a través de la razón le es dada la posibilidad de comprender aquel orden moral que se encuentra más allá del orden físico. Este entendimiento del orden

2 Es el caso de la pervivencia del escolasticismo de Tomás de Aquino, muy influyente en el derecho privado, Jean Bodín y el preceptor de Luis XV, Jacques Benigno Boussuet, en la iuspublicística. Cfr. Fernández Bulté, Julio, "Aproximación al pensamiento iusfilosófico de José Martí”, Revista Jurídica, La Habana, año 4, núm. 7, vol. 1, 2003, pp. 24-38.

3 Las especificidades de la relación colonia-metrópoli imponían tensiones irresolubles al pensamiento político español, violentando en las más de las veces la integridad de los contenidos desde los cuales se fundamentaban las posiciones de los liberales peninsulares. 
universal siempre es parcial, lo cual determina que se le impongan límites a su libertad. El alma humana está llamada a destinos trascendentes con respecto al mundo físico, esto determina la naturaleza humana, superior al resto de las criaturas, lo cual lo ubica en una posición de ventaja para servirse de ellas.

El ejercicio de la libertad estaba constreñido a la elección de las opciones que se le plantean desde el acto de conocimiento, del ejercicio de la razón. La elección es un acto perfecto de la voluntad, que presupone un acto de la razón superior humana. Lo justo se encontraba en la propia naturaleza humana, al ser el hombre sólo un segmento del universo y del orden cósmico, y al mismo tiempo, consciente de las determinaciones que lo someten. Para conocer la justicia, todo hombre debe centrarse en sí mismo, ubicando su lugar exacto dentro del orden universal, estableciendo las formas de obrar que le corresponden teniendo en cuenta su naturaleza específica, y los fines que se derivan de ésta. El progreso y la perfección humana conformarían la tradición, legado doctrinal que en el caso de lo hispánico tiene su raíz en la cristiandad.

En la obra de Magín Ferrer, Las leyes fundamentales de la Monarquía española, según fueron antiguas, y según conviene que sean en la época actual, se establece una síntesis de las ideas centrales de esta corriente ideológica en cuanto a la política y el derecho: la primacía del Derecho natural, la idea de una sociedad autárquica, la existencia de un pluralismo social no político, la configuración del orden jurídico desde la antropología cristiana, y el carácter de los fueros como conjunto de libertades concretas, y barrera para impedir el abuso de la autoridad.

Un baluarte del tradicionalismo español en la isla lo representó la Iglesia católica, su doctrina siguió fungiendo como una de las principales fuentes legitimadoras del poder colonial español. ${ }^{4}$ Este con-

4 Enrique Gil y Robles es uno de los más prominentes representantes de esta corriente dentro de la filosofía del derecho española, y con una amplia influencia dentro de Cuba gracias a la difusión de su doctrina por medio del aparato del Estado colonial. En su libro Tratado de derecho político según los principios de la filosofía y el derecho cristiano, sostiene la idea de que el fundamento último del derecho es Dios, luego la naturaleza humana, por lo que junto a la ley humana encontramos la ley divina y natural, en la correspondencia con esta última está la legitimidad de cualquier institución humana. 


\section{VLADIMIR PITA SIMÓN}

cordato estaba en sintonía con las ideas del papa León XIII, que propugnaba la necesidad de salvar la autoridad ideológica de la Iglesia, lo cual pasaba necesariamente por plantearse la recomposición de las relaciones de Roma con los sectores liberales burgueses europeos. Lo anterior exigía una modernización de la institución pero siempre manteniendo sus puntos de vista reaccionarios en cuanto a la filosofía política y del derecho. El eje de la teoría política y de la filosofía del derecho de la Iglesia católica española en la isla era el presupuesto de la sumisión del individuo a la autoridad colonial a partir del origen divino de este poder. ${ }^{5}$

\section{EL IUSNATURALISMO REFORMISTA DE LOS AUTONOMISTAS}

El derecho natural se constituyó en uno de los elementos centrales del pensamiento liberal cubano, tanto el independentista como el autonomista. Las diferencias no eran de fundamentación filosófica, y sí de formas practicas de garantizar los derechos y la dignidad humana. Los primeros buscaban la totalidad de los derechos del individuo como ciudadano de un Estado plenamente soberano, y los segundos buscaban formas asimilistas, o de ciertos grados de autonomía, dentro del esquema de poder existente, recurriendo a la idea de la evolución de las instituciones humanas.

Los autonomistas buscaban ante todo cambios en las instituciones de gobierno que le dieran cabida en la administración isleña, y no una sustitución de las relaciones económicas y sociales existentes, con una consabida transformación en el derecho privado en el cual se sostenían. Las figuras del autonomismo que explícitamente se refirieron a temas filosóficos del derecho, y concretamente a la temática del derecho natural fueron: Pablo Desvernine, Calixto Bernal, Antonio Barchiller y Morales, y Rafael Montoro.

5 La posición conservadora de la jerarquía de la Iglesia católica cubana en la época se nos hace evidente en la circular del 16 de abril de 1879, en la cual el vicario capitular de La Habana señala al acto revolucionario del pueblo cubano como una conculcación de la ley santa de Dios, y a la Revolución misma como un castigo celestial. 
Rafael Montoro fue el principal ideólogo del Partido Liberal Autonomista, y el encargado, junto con otros miembros de su élite intelectual, de estructurar el programa político de los reformistas cubanos en la segunda mitad del siglo XIX. En su artículo "Estudios fundamentales de derecho", prólogo a un libro de Pablo Desvernine, se enfrenta a los criterios sostenidos por la escuela histórica del derecho en cuanto al tema de las fuentes de los principios jurídicos supremos. Sostiene que estos principios se encuentran en la razón y en la conciencia humana; que se revelan por intuición y por la evidencia interior a cada hombre civilizado como norma natural de sus actos, como eternos principios de equidad y justicia.

Montoro se encuentra dentro del espectro ideológico del conservadurismo criollo, y sus posiciones iusfilosóficas sirvieron de fundamento a la desconfianza manifiesta del grupo político al que representaba, en cuanto a la capacidad de pueblo cubano a ejercer su independencia. Se apoya en Hegel para ubicar al cubano dentro de la clasificación de los pueblos incapaces de mantener su libertad por no estar dentro del grupo de aquellos Estados fuertes, que habían logrado el máximo desarrollo del espíritu nacional, y llamados a guiar a aquellos que no lo habían logrado. Su hegelianismo le sirve como sostén justificativo del régimen autonómico.

El rechazo del hecho revolucionario encuentra su base en la racionalidad trascendente de la historia, que a través del proceso dialéctico realiza el plan divino, donde las realidades no deseadas de la colonia vendrían a ser su antítesis, es decir, su negación, dentro de un viraje histórico que contempla la legalidad natural recogida en las realizaciones del Estado. La colonia cubana y el resto de las jóvenes repúblicas latinoamericanas no presentaban, según Montoro, un Estado que garantizara la unidad de las vidas individuales como concreción autoritaria de la voluntad general y la corrección moral. La inserción de nuestros pueblos a en la tendencias propias de la humanidad como concreción del espíritu absoluto sería desde la posición de subordinación a naciones más poderosas y prosperas, ya sea la monárquica España o la república norteamericana. La disconformidad debía manifestarla el cubano dentro de los límites de la legalidad colonial, con el único horizonte de las reformas, sin ir más allá. 


\section{VLADIMIR PITA SIMÓN}

Antonio Bachiller y Morales ${ }^{6}$ es una de las figuras más prominentes de la intelectualidad cubana del siglo XIX, y en su prolífica obra encontramos su libro Elementos de la filosofía del derecho, también conocido por Curso de derecho natural. Este manual hace un recorrido por las escuelas filosóficas del derecho, existentes hasta la primera mitad del siglo XIX, moviéndose siempre conceptualmente dentro del iusnaturalismo racionalista arraigado en Cuba. Realiza en su obra una crítica a los fundamentos irracionales de la escuela histórica, señalando que Savigny no ve en el derecho una creación reflexiva y voluntaria, poniéndolo fuera del arbitrio del hombre y de la sociedad. Propone la noción de la esencia del derecho, de profunda influencia teológico-cristiana, como una idea producida por la razón cuando es aplicada a los actos humanos. La razón se ratifica en su pensamiento como el instrumento para descubrir la ley vista como un ordenamiento eterno de la Providencia, que contribuyó a la armonía universal de la creación.

Otro importante filósofo del derecho del campo autonomista fue Calixto Bernal, diputado a Cortes por Santa Clara y compañero de José Martí durante el destierro, pública su principal obra iusfilosófica en Madrid en 1877. En ella fundamenta la realidad del Derecho natural en la evidencia de la existencia humana anterior al surgimiento de la ley positiva como institución social. ${ }^{7}$

\section{EL PENSAMIENTO IUSFILOSÓFICO REVOLUCIONARIO DE JOSÉ MARTÍ}

José Martí fue el principal ideólogo de la corriente independentista cubana a fines del siglo XIX. Su discurso político-jurídico, visto

6 Antonio Bachiller y Morales (1812-1889) fue uno de los más destacados intelectuales cubanos del siglo XIX. Fue catedrático de Derecho Canónico, Derecho natural y fundamentos de la religión en la Universidad de la Habana.

7 "El hombre tiene derechos adictos a la naturaleza, y esos derechos son anteriores e independientes de la sociedad y las leyes. La ley emana del derecho. Este derecho, como natural y anterior a todo, debe haberlo recibido el hombre de la naturaleza, desde su creación, antes de que se reuniera en sociedad organizada y se gobernase por leyes". Cfr. Vitier, Medardo, Las ideas en Cuba. La filosofía en Cuba, La Habana, Editorial de Ciencias Sociales, 2002, p. 130. 
como aquella construcción ideológica orientada a la sustentación y argumentación de un programa de acción, y de un modelo organizativo centrado en la consecución de la independencia nacional, está presente en todas las formas expresivas de la obra martiana.

La unicidad temática de fondo, en cuanto a los fines siempre presentes de la libertad tanto de la patria, como del hombre de manera general, le brinda a toda su producción intelectual, política y de vida, una alta organicidad. El método de construcción intelectual martiano, del permanente diálogo entre cultura y contexto, es un elemento consustancial a la asunción practica de los retos que la realidad le impone. Es por esto que para él, los valores políticos y jurídicos ocupan un lugar preeminente como instancias de la legitimidad y validez de toda construcción social. Esta estimativa jurídica martiana se resuelve a través de una original jerarquización de este plexo de valores, que es desplegado sobre la realidad presente y la deseada, funcionando como instancia orientadora a la vez de la conducta, y de su cosmovisión.

Dentro del conjunto ideológico-normativo martiano, las categorías propias de lo que se entiende por filosofía del derecho tienen un espacio importante dentro de su estrategia de argumentación. Los contenidos iusfilosóficos del discurso político-jurídico martiano, resultan una instancia fundamental de legitimación, como mediación primaria de la praxis social y política.

La centralidad que adquiere lo humano dentro de su sistema ideológico, realza lo normativo a una posición de mediación fundamental del conjunto de sus ideas. Tanto la moral como el derecho, como aquellos dos órdenes normativos humanos principales, pasan a ser momentos significativos de la realización humana, en la consecución de un estatus existencial desalienado en un sentido amplio y esencial. Estos aparecen en el discurso político-jurídico martiano indiferenciados en lo esencial, presentándose lo teleológico, lo axiológico y lo jurídico-formal, estrechamente relacionados. Lo anterior realza la importancia que da Martí a los criterios valorativos en la conformación del cuerpo de conceptos referentes al derecho positivo y a la institucionalidad político-jurídica. Esta última encuentra los criterios de su validez en la realización efectiva de los valores jurídicos, en la capacidad de ser vehículo eficaz para la consecución 


\section{VLADIMIR PITA SIMÓN}

de los fines de la vida dentro del marco de las relaciones intersubjetivas humanas.

Martí mantiene el plexo axiológico-jurídico tradicional, con la justicia como valor central y superior, modulador del despliegue del resto de los valores jurídicos. Los mismos, dado el marco de relaciones prácticas desde donde se generan sus contenidos, poseen una fuerte impronta política. Es por lo que es correcto referirse a los mismos como valores político-jurídicos, dado que no son propiamente elementos característicos de la capacidad operacional de un sistema jurídico, con una orientación puramente técnica. Actúan preferentemente como elementos legitimadores de un orden aún no realizado, de una deontología de lo intersubjetivo que se despliega hasta lo institucional, dentro del modelo de república enarbolado por él.

Dentro del conjunto de fines para la vida humana, dos son los que orientan el conjunto del actuar intersubjetivo humano, especialmente en la esfera jurídica y la política. El primero es el de la independencia, dentro de la cual se manifiesta el principio de autonomía de la voluntad y la libertad, como imperativo existencial. ${ }^{8}$ El segundo es el de la consecución de la dignidad plena del hombre, como forma civilizada y culta de garantizar el equilibrio dentro del conjunto de las relaciones sociales, y la plena emancipación humana. Ambos fines los ve sintetizados en un fin humano supremo, la felicidad. ${ }^{9}$ Esta felicidad impone su búsqueda a través del ejercicio prudente de la razón. ${ }^{10}$

Teniendo en cuenta el papel de la armonía dentro de la cosmovisión martiana y su traducción del equilibrio, como estado natural y deseado del orden social, se encuentra el fundamento de la centralidad de la justicia dentro del conjunto de los valores enarbolados. Es

8 "La independencia es condición de esencia de la vida: todo sea libre, sin más esclavitud que la lógica en la vida literaria y en la vida del deber...". Cfr. Martí, José, Obras completas, La Habana, Editorial de Ciencias Sociales, 1991, t. 6, p. 442.

9 "La felicidad tiene garantía sólida en el concepto de independencia y dignidad humanas...." Ibidem, p. 222.

10 "La felicidad existe sobre la tierra; y se la conquista con el ejercicio prudente de la razón, el conocimiento de la armonía del universo, y la práctica constante de la generosidad.... Ibidem, p. 289. 
precisamente dentro del marco de la armonía social que la justicia nace como exigencia moral del respeto a los derechos fundamentales de todos. La misma posee particularidades impuestas por el método electivo aplicado a la construcción de sus contenidos concretos. Esto genera tensiones que buscan ser resueltas dentro del marco cosmológico. La presentación de la misma como la acomodación del derecho positivo al derecho natural se corresponde con su iusnaturalismo racionalista revolucionario. La justicia aparece como la ley humana suprema, que se encuentra más allá de las violencias propias de los hombres, generadas por la defensa egoísta de sus intereses. Esta violencia no es propia de la naturaleza de la justicia, sólo en función de lo justo se justifica la lucha, siendo esta un deber, movido por la necesidad de equidad, y por el empeño fundacional de aquellos hombres que en sus almas traen la necesidad de ella. La justicia actúa tras lo que se presenta como caótico y hostil ante nuestra percepción, y va unida estrechamente al ejercicio de la virtud. Ella es un elemento esencial del gran movimiento humano hacia su progreso; para Martí, toda obra colectiva de la voluntad humana debe tener un contenido de justicia. ${ }^{11}$

En esta concepción martiana de la justicia encontramos el reconocimiento del otro como condición de realización de lo justo, constituyéndose en elemento consustancial a la dignidad plena del hombre. Esta idea deriva en la necesidad de la igualdad de condiciones como requisito para el logro de la justicia social a partir de criterios de inclusión que parten de consideraciones sobre la contextura ética del individuo, y de los grupos humanos. Esta argumentación martiana de la igualdad se deriva de su idea de unidad ontológica dentro de la diversidad. Esto da paso a una concepción sustantiva de la igualdad, alejada de las fórmulas formales y procedimentales tradicionales del liberalismo de su tiempo. La igualdad es un valor, y a

11 Martí no podía ponderar una concepción conflictualista de las relaciones hacia el interior de la sociedad porque su referente es la realidad colonial y periférica de Cuba y de América Latina. No se daban en nuestras tierras las condiciones objetivas que llevaron a Carlos Marx a plantear sus propuestas teóricas. Esto se muestra acorde con las tareas históricas específicas que tuvo que enfrentar en medio de circunstancias también específicas. 


\section{VLADIMIR PITA SIMÓN}

la vez, una condición de posibilidad de la consecución de la felicidad como un fin existencial humano. ${ }^{12}$

El trato respetuoso al hombre se sustenta en "la igualdad del mérito" y "la igualdad plena de derechos", pero la primera de estas deviene en contenido de la segunda. La primera no se presenta como la condición de los iguales, en el mérito visto como un privilegio de los que disfrutan de una realidad o dignidad superior al común de los hombres, sino como la igualdad en el mérito derivado de la acción virtuosa, de la creación, del cumplimiento y la realización de la condición humana.

Si la independencia funciona dentro del esquema conceptual martiano a manera de fin e imperativo político-moral; la igualdad, a la vez de valor fundamental, funciona como imperativo social dado el contexto de desigualdad estructural en que debe realizarse la independencia cubana, y el desarrollo armonioso deseado para nuestra América y la humanidad. ${ }^{13}$

La igualdad de derechos para Martí ha de estar sustentada en una igualdad material, esencial pero equitativa, que afectará los elementos constitutivos de lo humano. Llegó a criticar los programas igualitaristas propios de algunos enfoques utopistas y socialistas que abogaban por soluciones asistencialistas y paternalistas extremas. A estas, a la vez que les critica la posibilidad de aumentar la carga burocrática y parasitaria del Estado, denunciaba la posibilidad del deterioro de la condición humana a causa del poco estímulo a la creación humana. ${ }^{14}$

12 “...las condiciones de la felicidad deben estar sinceramente abiertas, y con igualdad rigurosa, a todo el mundo". Ibidem, p. 159.

13 En la configuración de este valor interviene el conjunto de iniquidades, y condiciones reales de desigualdad económica, social y políticas de la colonia cubana, así como el conjunto de estas presenciadas por él en su peregrinar por América y Europa. Estas desigualdades estaban sustentadas en doctrinas políticas y jurídicas que naturalizaban las condiciones de explotación propias de las relaciones de producción capitalistas, como de aquellas que aún mostraban rasgos del feudalismo. La propia ideología liberal enarbolaba argumentos contrarios al sufragio universal, practicando el voto censitario excluyente, además del sostén de un Estado abstencionista alejado de la promoción de los derechos sociales, culturales o económicos.

14 Habla de la necesidad de: “ ...modos naturales de equilibrar la riqueza pública dividida con tal inhumanidad... que ha de mantener naturalmente la ira, descon- 
Su ideal de justicia arranca de presupuestos profundamente solidarios. Es la solidaridad martiana la explicitación del principio del ejercicio de la integridad propia y ajena. En la dimensión externa que se le da en la obra de Martí, se relaciona estrechamente con la defensa activa de los derechos, léase la dignidad y el decoro de los otros hombres. ${ }^{15}$

La libertad es una categoría principal en toda la argumentación iusfilosófica de José Martí, vista como una fuerza espontánea del espíritu progresista de la humanidad, señalada como "la religión nueva" que debe trascender "las redenciones formales". Esta última frase crítica, nos confirma sus aprensiones sobre los criterios positivistas que prevalecían hacia la segunda mitad del siglo XIX, y que mantuvieron su hegemonía ideológica durante gran parte del siglo XX. Ante esto propone que la "redención humana debe ser de esencias", superadora de las convenciones que "tuercen los sentimientos de los hombres". La liberación debe partir de lo espiritual para que se logre una real libertad política.

El valor de la libertad está anclado al concepto de independencia, que funciona en Martí como imperativo político-moral, y presupuesto necesario para toda acción del "hombre natural" cubano. La libertad es ante todo un premio al trabajo sostenido de la comunidad humana, un resultado del sacrificio y de la lucha por ella. ${ }^{16}$

Al mismo tiempo la conceptúa como el punto de partida para el desarrollo de todas las demás potencialidades humanas. Pero la libertad también nace del conocimiento de la naturaleza, y conse-

suelo y desesperación a seres humanos que se roen los puños de hambre en las mismas calles por donde pasean hoscos y erguidos otros seres humanos...". Ibidem, pp. 391 y 392.

15 Esto debe ser el resultado de una armónica identidad colectiva, contenida en su obra en el concepto de patria. "Patria es comunidad de intereses, unidad de tradiciones, unidad de fines, fusión dulcísima y consoladora de amores y esperanzas" Ibidem, p. 93. El patriotismo vendría a ser la correspondencia entre la dimensión íntima del ejercicio de la integridad propia, el pundonor, y la externa ya mencionada. "El patriotismo es, de cuantas cosas se conocen hasta hoy, (ha sido hasta ahora) la levadura mejor, (entre todas las conocidas), de todas las virtudes humanas". Ibidem, p. 377.

16 "La libertad ha de ser una práctica constante para que no degenere en una fórmula banal”. Ibidem, p. 340. 


\section{VLADIMIR PITA SIMÓN}

cuentemente, del desarrollo de las capacidades para accionar eficazmente sobre ella. Necesariamente debe ser un camino de educación la que conduzca al hombre al reino de la libertad. La educación es la forma universal por excelencia de obtención de la cultura. Cada hombre para ejercer su libertad ha de "ser una antorcha", "irradiar luces", es decir, cultura. ${ }^{17}$

Un elemento fundamental de la concepción martiana de la dignidad humana es el del ejercicio en favor de todos de la libertad de pensar. La capacidad libre de cada hombre es la base segura del desarrollo de la cultura, ajena siempre a todo criterio estático, y guiado en lo social por la capacidad del pensamiento a las demandas reales de cada pueblo y de la época. Esta finalidad colectiva la hace decorosa. $^{18}$

Los caminos americanos hacia la libertad son esencialmente diferentes a los europeos, y diferentes las formas de conseguir su afianzamiento. Califica a la libertad en Europa como una "rebelión del espíritu", dando cuenta del predominio de los criterios racionalistas en las ideologías del viejo continente; mientras que la libertad americana la concibe como una "vigorosa brotación", imagen referida a lo cercano que percibe el esfuerzo emancipatorio americano a las esencias naturales humanas, a los elementos más acordes con la emoción. ${ }^{19}$ El nexo que establece Martí entre el bienestar y la libertad es claro, el primero se convierte en condición indispensable de la

17 “...la primera libertad, base de todas, es la de la mente", ibidem, p. 348.

18 La defensa martiana de la libertad de pensamiento parte de la idea kantiana de la razón como argumentación de naturaleza libre, indefectiblemente crítica, no sometida a controles externos que pudieran afectar su función inquisitiva. Esta libertad es presentada por Martí como constitutiva del procedimiento racional de apropiación y transformación de la realidad, y previamente, como presupuesto necesario en la construcción del conocimiento verídico y punto de arrancada de la elección moral y del actuar útil a la humanidad.

19 Sólo justifica la vía violenta cuando no existe camino al ejercicio de los derechos, como es en el caso de las guerras de independencia de las tierras americanas. Explica el empleo de la fuerza como auxilio al derecho, para así evitar su muerte por desuso, dentro de la vida de las repúblicas latinoamericanas, como fenómeno propio de toda sociedad naciente, víctima siempre de los "caudillos brillantes e intrépidos". La fuerza es un recurso que sólo es legítima cuando se utiliza "para hacer el bien". Es deber de ella el respeto a la debilidad. 
segunda. Su idea de que "la humanidad asciende cuando adelanta", reafirma lo estrechamente interrelacionado de ambas condiciones.

Esta idealidad de lo jurídico en Martí se construye en parte desde los principios éticos del obrar humano, que dentro de la formulación de la institucionalidad cubana se manifiesta como caracteres propios de la identidad de la nación. No encontramos en Martí un esfuerzo lógico por la búsqueda del ser del derecho. No se evidencia la aplicación del método deductivo, y la intención del rigorismo propio del intento de lograr una definición del fenómeno derecho, en la cual se destaque la adecuación del pensamiento con él mismo. Su reflexión parte de un conjunto de certezas derivadas de la utilización de la intuición como método.

Martí, como todo iusnaturalista, parte desde la moral para construir su visión sobre el derecho. No es central el problema de distinguir lo moral de lo propiamente jurídico. Su derecho natural es concebido como lo bueno o justo que se refleja en el orden de las relaciones humanas. Es la justeza del derecho requisito esencial de su validez. No reduce el proceso de creación del derecho a la simple subsunción de circunstancias vitales a la norma legal como proceso netamente lógico y formal. Reconoce el papel de las circunstancias cambiantes, espacial e históricamente, de las comunidades humanas, así como de sus tradiciones y cultura, como elementos importantes en la conformación de un derecho que acepta momentos intuitivos y preconceptos de arrancada, fundamentalmente de naturaleza ética.

Lo jurídico en su pensamiento deja espacio a lo emotivo, al sentimiento jurídico. Su iusfilosofía está abierta a contenidos esenciales, sin dejar de lado a la forma jurídica. Esto permite que aparezca en su obra la idea de un derecho que acepta a la justicia como imperativo. El objetivo primordial del derecho para Martí es el de apuntar hacia la realización práctica y vital de la justicia, y como ciencia, éste debe concentrarse en la investigación, como parte de la incentivación para la práctica, de aquellas leyes que participan del deber ser de lo humano. La confusión de moral y derecho es consustancial a la identificación en el pensamiento martiano de ambas dimensiones de lo normativo como principios constitutivos del obrar. Su deontología jurídica es una valoración moral de lo que concibió como dere- 


\section{VLADIMIR PITA SIMÓN}

cho, y la realización plena de este orden de relaciones humanas sólo sería posible en una República de naturaleza moral.

\section{A MANERA DE CONCLUSIONES}

La cultura política presente en la isla y en las emigraciones para la segunda mitad del siglo XIX, permitió la modelación acelerada del Estado-nación cubano, prefigurándolo en diversas dimensiones, dentro de las cuales la político-jurídica es central. Sin duda alguna, el catalizador de este proceso fue las guerras de independencia, y con ello la agudización del sistema de contradicciones presentes en la colonia cubana a niveles tales de conflictividad que volvieron insostenible el sistema de relaciones políticas establecidas entre Cuba y España.

Dentro de este proceso de conformación de la identidad de lo cubano, la articulación de una identidad ciudadana, a contrapelo de la existente de súbdito, permitió la estructuración práctica de los contenidos elaborados por las elites políticas que se debatían entre la solución autonomista y la independentista. Esta última corriente enarbolaba formas democráticas de participación política como única garantía para la consecución de contenidos teleológicos esenciales, sintetizados en su variante más democrática en el pensamiento de José Martí, y que superaría los marcos de los derechos civiles y políticos planteados en el ideario de la burguesía cubana.

La adscripción general de la intelectualidad criolla al iusnaturalismo racionalista, está determinado por la realidad ideológica de que todas las posiciones iusfilosóficas de Cuba en la segunda mitad del siglo XIX, están condicionadas por el imperativo político impuesto por la inviabilidad del modelo colonial. Esto denota un cierto retraso del pensamiento jurídico con respecto al pensamiento filosófico que en general era manejado dentro de la isla. Este iusnaturalismo racionalista permitía una línea de argumentación de las propuestas de superación del estado de cosas, lo cual explica su hegemonía ideológica, y el no avance sustancial de otras escuelas, especialmente el positivismo jurídico. Cuba mostraba un desfase con respecto al resto de las repúblicas latinoamericanas, que expe- 
rimentaban el avance de las diversas formas de iuspositivismo, y en las cuales se ensayaban los primeros pasos de la revuelta anti-formalista latinoamericana.

VII. BIBLIOGRAFÍA

CEPEDA, Rafael, Lo ético-cristiano en la obra de José Martí, Matanzas, CEHILA, 1992.

Colectivo de Autores, El krausismo y su influencia en América Latina, Madrid, Fundación Friedrich Ebert, 1989.

Colectivo de Autores, Pensamiento español y latinoamericano contemporáneo, Santa Clara, Editorial Feijóo, Universidad Central de Las Villas, 2006, 2 ts.

Di Cagno, Vittorio, Martí Jurista, La Habana, Centro de Estudios Martianos, 2003.

Estrade, Paul, José Martí. Los fundamentos de la democracia en Latinoamérica, Madrid, Ediciones Doce Calles, 2002.

Estrade, Paul, Martí en su siglo y en el nuestro, La Habana, Centro de Estudios Martianos, 2008.

FERnÁNDEz Bulté, Julio, “Aproximación al pensamiento iusfilosófico de José Martí", Revista Jurídica, La Habana, año 4, núm. 7, vol. 1, 2003.

FERnÁNDEz Bulté, Julio, Filosofía del derecho, La Habana, Editorial Félix Varela, 2003.

FERnÁndez Bulté, Julio, Julio, Historia del Estado y el derecho en Cuba, La Habana, Editorial Félix Varela, 2005.

FERNÁNDEz RETANAR, Roberto, Introducción a José Martí, La Habana, Letras Cubanas, 2006.

Fornet-Betancourt, Raúl, Aproximaciones a José Martí, Aquisgrán, Mainz, 1998.

MARTí, José, Obras completas, La Habana, Editorial de Ciencias Sociales, 1991. 
Monal Rodríguez, Isabel y Miranda, Olivia, La Habana, Pensamiento cubano, siglo XIX, Editorial de Ciencias Sociales, 2002, 2 ts.

Rivas Poll, Elena, Pensamiento filosófico de José Martí. Un estudio desde las mediaciones político-axiológicas, La Habana, Editorial de Ciencias Sociales, 2008.

Torre Molina, Mildred de la, El autonomismo en Cuba. 1878-1898, La Habana, Editorial de Ciencias Sociales, 1997.

Vitier, Medardo, Las ideas en Cuba. La filosofía en Cuba, La Habana, Editorial de Ciencias Sociales, 2002. 